\title{
Proceedings
}

\section{Synthesis of New 2-Oxonicotinic acids}

\author{
Victor V. Dotsenko ${ }^{1,2,3, *}$, Alena A. Russkih ${ }^{1}$ and Nicolai A. Aksenov ${ }^{3}$
}

1 Kuban State University, 149 Stavropolskaya str, 350040 Krasnodar, Russia;

2 ChemEx Lab, Vladimir Dal' Lugansk National University, 20A/7 Molodezhny, 91034 Lugansk, Russia

3 Department of Chemistry, North Caucasus Federal University, 1a Pushkin St., 355009 Stavropol, Russia;

* Correspondence: victor_dotsenko@bigmir.net

† Presented at the 24th International Electronic Conference on Synthetic Organic Chemistry, 15 November15 December 2020; Available online: https://ecsoc-24.sciforum.net/.

Published: date

\begin{abstract}
Dimethyl-5-((phenylamino)methylene)-1,3-dioxane-4,6-dione, prepared by ternary condensation of Meldrum's acid with triethyl orthoformate and aniline, reacts with $\mathrm{N}$-aryl cyanoacetamides in the presence of $\mathrm{KOH}$ to give 2-oxo-1,2-dihydropyridine-3-carboxylic acids, which are useful as drug precursors or perspective ligands.
\end{abstract}

Keywords: nicotinic acids; Meldrum's acid; 2-oxo-1,2-dihydropyridine-3-carboxylic acid; cyanoacetamides

\section{Introduction}

Nicotinic acid (niacin, vitamin PP) and its derivatives have been recognized to have a wide spectrum of biological activity. Thus, nicotinic acid and derivatives were used for treatment of hyperlipoproteinemia, and posess hypocholesterolemic, neuroprotective, antitumor and other effects [1-4]. 2-Oxo-1,2-dihydropyridine-3-carboxylic acids are less studied; however, they are of interest as complexing agents [5,6] and as pharmaceuticals [7]. Earlier we described [8] the method for preparation of 5-cyano-6-mercapto-2-oxo-1,2-dihydropyridine-3-carboxylic acid 1 starting from Meldrum's acid 2 (for reviews see [9-14]) and cyanothioacetamide 3 [15,16] (Scheme 1).

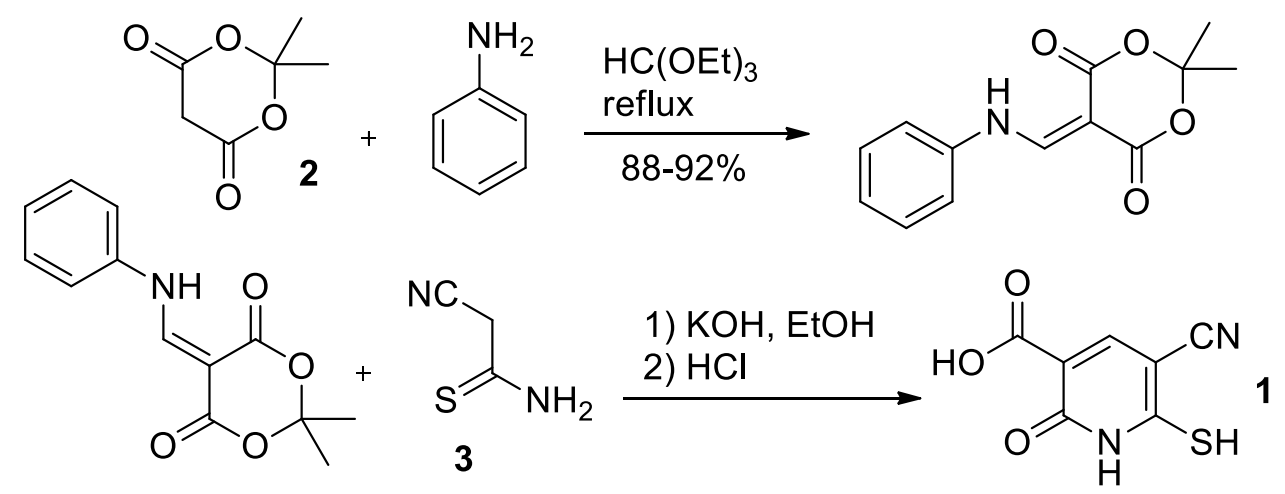

Scheme 1. The reaction of cyanothioacetamide with anilinomethylidene Meldrum's acid.

Using $\mathrm{N}$-substituted cyanoacetamides 4 instead of cyanothioacetamide 3 , we succeeded to prepare new $\mathrm{N}$-aryl 2-oxonicotininc acids 5 . The reaction proceeds smoothly in the presence of $\mathrm{KOH}$ in alcohols. The treatment of the dipotassium salts formed liberated free acids 5 (Scheme 2). Cyanoacetamides 4 were prepared by cyanoacetylation of primary amines with cyanoacetylpyrazole 6 [17-19]. 
<smiles>Cc1cc(C)[nH]n1</smiles><smiles>CC1(C)OC(=O)C(=CNc2ccccc2)C(=O)O1</smiles><smiles>[R]Oc1c(C#N)cc(C(=O)[O-])c(=O)n1[R]</smiles>

Scheme 2. The reaction of $\mathrm{N}$-substituted 2-cyanoacetamides 4 with 2,2-dimethyl-5(phenylamino)methylene-1,3-dioxane-4,6-dione.

\section{Experimental}

\subsection{2,2-Dimethyl-5-(phenylamino)methylene-1,3-dioxane-4,6-dione}

A mixture of the powdered Meldrum's acid $(14.0 \mathrm{~g}, 0.1 \mathrm{~mol})$, triethyl orthoformate $(21.6 \mathrm{~mL}, 0.13$ $\mathrm{mol})$, and freshly distilled aniline $(9.1 \mathrm{~mL}, 0.1 \mathrm{~mol})$ was refluxed with vigorous stirring for $5 \mathrm{~min}$ to afford a syrupy reaction mass. It was diluted with $30 \mathrm{~mL}$ of EtOH and refluxed for an additional 3 min. Then, it was cooled with stirring to $\sim 20{ }^{\circ} \mathrm{C}$ and diluted with water to $100 \mathrm{~mL}$. After $2 \mathrm{~h}$, the product was filtered off and washed with water, twice with $60 \% \mathrm{EtOH}$, and with hexane. Yield $92 \%$, m.p. $156-157^{\circ} \mathrm{C}$. Found (\%): C, 63.19; H, 5.32; N, 5.66. $\mathrm{C}_{13} \mathrm{H}_{13} \mathrm{NO}_{4}$. Calculated (\%): C, 63.15; H, 5.30; N, 5.67. ${ }^{1} \mathrm{H}$ NMR, $\delta: 1.70$ (s, $\left.6 \mathrm{H}, 2 \mathrm{Me}\right) ; 7.19-7.51(\mathrm{~m}, 5 \mathrm{H}, \mathrm{Ph}) ; 8.58(\mathrm{~d}, 2 \mathrm{H},-\mathrm{CH}=, 3 \mathrm{~J}=14.7 \mathrm{~Hz}) ; 11.27$ (d, $\left.1 \mathrm{H}, \mathrm{NH},{ }^{3} \mathrm{~J}=14.7 \mathrm{~Hz}\right)$.

\subsection{Compounds 5 (General Procedure)}

Potassium hydroxide $(0.45 \mathrm{~g}, 0.008 \mathrm{~mol})$ was added to a vigorously stirred suspension of 2,2dimethyl-5-(phenylamino)methylene-1,3-dioxane-4,6-dione $(0.004 \mathrm{~mol})$ and corresponding cyanoacetamide $(0.004 \mathrm{~mol})$ in $10 \mathrm{~mL}$ of $\mathrm{EtOH}$ (or $\mathrm{BuOH})$. After $24 \mathrm{~h}$, the slurry of deposited dipotassium salt was acidified with concentrated $\mathrm{HCl}$ to adjust $\mathrm{pH}$ value to 3.0 and maintained for 3 $\mathrm{h}$. The precipitate formed was filtered off to give $\mathrm{N}$-aryl 2-oxonicotininc acids $\mathbf{5}$.

\section{References}

1. Carlson, L.A. Nicotinic acid: The broad-spectrum lipid drug. A 50th anniversary review. J. Intern. Med. 2005, 258, 94-114.

2. Julius, U.; Fischer, S., Nicotinic acid as a lipid-modifying drug-A review. Atheroscler. Suppl. 2013, 14, 7-13.

3. Prousky, J.; Seely, D. The treatment of migraines and tension-type headaches with intravenous and oral niacin (nicotinic acid): Systematic review of the literature. Nutr. J. 2005, 4, 3.

4. Snaidr, V.A.; Damian, D.L.; Halliday, G.M. Nicotinamide for photoprotection and skin cancer chemoprevention: A review of efficacy and safety. Exp. Dermatol. 2019, 28, 15-22.

5. Di Marco, V.B.; Tappro, A.; Dolmella, A.; Bombi, G.G. Complexation of 2-hydroxynicotinic and 3hydroxypicolinic acids with zinc (II). Solution state study and crystal structure of trans-diaqua-bis-(3hydroxypicolinato) zinc (II). Inorg. Chim. Acta 2004, 357, 135-142. 
6. Yoshito, O.; Fumiaki, H.; Yoshihiro, T.; Takayasu, K. Studies on the interaction of pyridone carboxylic acids with metals. Chem. Pharm. Bull. 1992, 40, S692-S696.

7. Fossa, P.; Menozzi, G.; Dorigo, P.; Floreani, M.; Mosti, L. Synthesis and pharmacological characterization of functionalized 2-pyridones structurally related to the cardiotonic agent milrinone. Bioorg. Med. Chem. 2003, 11, 4749-4759.

8. Dotsenko, V.V.; Krivokolysko, S.G.; Chernega, A.N.; Litvinov, V.P. Anilinomethylidene derivatives of cyclic 1,3-dicarbonyl compounds in the synthesis of new sulfur-containing pyridines and quinolines. Russ. Chem. Bull. 2002, 51, 1556-1561.

9. Ivanov, A.S. Meldrum's acid and related compounds in the synthesis of natural products and analogs. Chem. Soc. Rev. 2008, 37, 789-811.

10. Pair, E.; Cadart, T.; Levacher, V.; Brière, J.F. Meldrum's Acid: A Useful Platform in Asymmetric Organocatalysis. ChemCatChem 2016, 8, 1882-1890.

11. Lipson, V.V.; Gorobets, N.Y. One hundred years of Meldrum's acid: Advances in the synthesis of pyridine and pyrimidine derivatives. Mol. Divers. 2009, 13, 399-419.

12. McNab, H. Meldrum's acid. Chem. Soc. Rev. 1978, 7, 345-358.

13. Chen, B.C., Meldrum's acid in organic synthesis. Heterocycles 1991, 32, 529-597.

14. Strozhev, M.F.; Neiland, O.Y. 1,3-Dioxane-4,6-diones in organic synthesis. Chem. Heterocycl. Compd. 1991, 27, 457-473.

15. Litvinov, V.P. Cyanoacetamides and their thio- and selenocarbonyl analogues as promising reagents for fine organic synthesis. Russ. Chem. Rev. 1999, 68, 737-763.

16. Dyachenko, V.D.; Dyachenko, I.V.; Nenajdenko, V.G. Cyanothioacetamide: A polyfunctional reagent with broad synthetic utility. Russ. Chem. Rev. 2018, 87, 1.

17. Chigorina, E.A.; Dotsenko, V.V.1-Cyanoacetyl-3, 5-dimethylpyrazole-effective cyanoacetylating agent and a new building block for the synthesis of heterocyclic compounds. Chem. Heterocycl. Compd. 2012, 48, 11331152.

18. Chigorina, E.A.; Dotsenko, V.V. Novel reactions of 1-cyanoacetyl-3, 5-dimethylpyrazole. Chem. Heterocycl. Compd. 2020, 56, 302-304.

19. Chigorina, E.A. 1-Cyanoacetyl-3, 5-dimethylpyrazole. Synlett 2014, 25, 453-454.

Publisher's Note: MDPI stays neutral with regard to jurisdictional claims in published maps and institutional affiliations.

(C) 2020 by the authors. Submitted for possible open access publication under the terms and conditions of the Creative Commons Attribution (CC BY) license

(http://creativecommons.org/licenses/by/4.0/). 